\title{
SISTEM INFORMASI AKADEMIK BERBASIS DEKSTOP PADA MADRASAH ALIYAH AR-RAHMAH SUNGAI TABUK
}

\author{
Mayang Sari, S.Kom, M.Kom \\ mayang@fti.uniska-bjm.ac.id \\ Yusri Ikhwani, S.Kom, M.Kom \\ yusri@fti.uniska-bjm.ac.id
}

\begin{abstract}
ABSTRAK
Madrasah Aliyah Ar-Rahmah Sungai Tabuk merupakan salah satu sekolah swasta yang tak luput dari dampak perkembangan teknologi informasi. Kebutuhan akan teknologi informasi menuntut setiap instansi baik negeri maupun swasta untuk perlu meningkatkan kulalitas sumber daya manusia dalam menjalankan sistem yang sedang berlangsung demi meningkatkan kualitas dan daya saing.

Dengan adanya dukungan sistem komputerisasi, sistem pengolahan data yang sebelumnya dilakukan dengan cara manual menjadi lebih efisien, serta pengolahan data akan dapat dilakukan dengan baik dan hasil yang sempurna, yang mana selama ini pada Madrasah Aliyah Ar-Rahmah Sungai Tabuk pengolahan data masih menggunakan Microsoft Word dan Microsoft Exel. Dari kegiatan administrasi yang tidak optimal serta penyimpanan data yang berbentuk formulir kertas yang disimpan di lemari arsip menyebabkan lambatnya proses pencarian dan penyajian data yang dibutuhkan, dan mengakibatkan banyaknya waktu yang terbuang.

Pembangunan program aplikasi Sistem Informasi Akademik ini menggunakan bahasa pemrograman Visual Basic 6.0. Sistem ini berguna untuk mengelola data akademik siswa yang dapat menghemat waktu dan mengefisienkan kinerja serta dapat mencegah terjadinya kehilangan berkas-berkas siswa.
\end{abstract}

Kata kunci : Akademik, Pengolahan Data, Ar-Rahmah

\section{PENDAHULUAN}

Teknologi saat ini memiliki peranan yang sangat penting di dalam kehidupan sehari-hari yang mencakup berbagai macam bidang yang ada di masyarakat, perkembangan teknologi informasi yang semakin modern menuntut setiap instansi baik negeri maupun swasta perlu meningkatkan kulalitas sumber daya manusia dalam menjalankan sistem yang sedang berlangsung demi meningkatkan kualitas dan daya saing. Salah satu yang terkena dampak perkembangan teknologi informasi adalah sekolah yang mana sistem informasi merupakan alat bantu yang diperlukan dalam lembaga pendidikan yang menjadi kebutuhan mutlak dan dapat memberikan keunggulan kompetitif, sehingga menjadi prioritas tertinggi.

Dengan adanya dukungan sistem komputerisasi, sistem pengolahan data yang sebelumnya dilakukan dengan cara manual menjadi lebih efisien, serta pengolahan data akan dapat dilakukan dengan baik dan hasil yang sempurna. Selain itu juga memiliki ketelitian yang 
tinggi sehingga akan memudahkan dan tidak memakan biaya waktu yang lama dalam pencarian data yang di perlukan.

Pada Madrasah Aliyah Ar-Rahmah selama ini penyajian dan pengolahan datanya masih menggunakan program aplikasi yang sederhana seperti pengolahan nilai siswa dan penyimpanan data siswa yang tidak teratur sehingga untuk memperoleh informasi yang dibutuhkan terkadang harus mencarinya satu persatu.

Hal itu disebabkan karena pengolahan data masih menggunakan Microsoft Word dan Microsoft Exel. Dari kegiatan administrasi yang tidak optimal serta penyimpanan data yang berbentuk formulir kertas yang disimpan di lemari arsip menyebabkan lambatnya proses pencarian dan penyajian data yang dibutuhkan, dan mengakibatkan banyaknya waktu yang terbuang.

Berdasarkan latar belakang diatas maka akan dilakukan penelitan dengan judul "SISTEM INFORMASI AKADEMIK BERBASIS DEKSTOP PADA MADRASAH ALIYAH ARRAHMAH SUNGAI TABUK" yang di harapkan dapat mempermudah dalam pengumpulan data siswa, pengolahan data siswa, penyimpanan data siswa serta untuk menyalurkan informasi yang lebih efektif dan efesien.

\section{RUMUSAN MASALAH}

Berdasarkan latar belakang judul yang dipilih, maka perumusan masalah dalam penelitian ini adalah :

1. Penyajian dan pengolahan data pada Madrasah Aliyah Ar-Rahmah Sungai Tabuk saat ini masih menggunakan program aplikasi Ms. Word dan Ms. Excel.

2. Lambatnya proses pencarian dan penyajian data pada Madrasah Aliyah Ar-Rahmah Sungai Tabuk.

\section{TUJUAN PENELITIAN}

Tujuan yang ingin dicapai dalam penelitian ini adalah sebagai berikut :

1. Merancang dan membangun sistem informasi akademik yang berfungsi untuk mengelola data siswa dan akademik pada Madrasah Aliyah Ar-Rahmah Sungai Tabuk.

2. Meningkatkan efektifitas layanan informasi pada Madrasah Aliyah Ar-Rahmah Sungai Tabuk.

\section{TARGET LUARAN DAN MANFAAT PENELITIAN}

Target luaran dalam penelitian ini adalah agar nantinya penelitian ini dapat dipublikasikan ke dalam jurnal local maupun jurnal nasional. Sedangkan manfaat yang ingin dicapai dalam penelitian ini adalah sebagai berikut :

1. Penyajian dan pengolahan data pada Madrasah Aliyah Ar-Rahmah Sungai Tabuk dapat disajikan dalam bentuk terkomputerisasi.

2. Proses pencarian dan penyajian data pada Madrasah Aliyah ArRahmah Sungai Tabuk dapat lebih cepat dan efisien

\section{METODE PENELITIAN}

Metode yang digunakan dalam membangun penelitian ini adalah menggunakan metode Action Research yang bertujuan untuk memecahkan masalah agar segera dapat diambil tindakan perbaikan.

Langkah-langkah pembuatan perangkat lunak ini antara lain :

1. Mempelajari sistem yang berjalan pada Madrasah Aliyah Arrahmah Sungai Tabuk.

2. Menganalisa kebutuhan-kebutuhan sistem yang akan dibuat

3. Membuat perancangan model sistem.

4. Merancang interface untuk perangkat lunak simulasi. 
5. Merancang dan membuat analisis kebutuhan sistem baru

6. Melakukan pengujian dan pengetesan terhadap perangkat lunak hasil rancangan.

\section{ANALISA HASIL DAN PEMBAHASAN}

\section{Hasil Penelitian}

Pada dasarnya usulan perancangan sistem yang dibuat banyak berubah dari sistem yang berjalan. Usulan sistem yang dirancang berubah pengolahan data yang selama ini dilakukan belum secara terkomputerisasi menjadi pengolahan data yang dilakukan dengan bantuan komputer. Perancangan sistem ini meliputi diagram konteks, diagram alir data, tahap perancangan ini akan memberikan gambaran mengenai aliran informasi dan proses yang sedang berjalan dalam sistem.

\section{Gambaran Sistem Usulan}

Perancangan prosedur merupakan perancangan sistem secara umum yang memberikan gambaran kepada user tentang sistem yang baru. Berikut perancangan prosedur yang diusulkan :

1. Data siswa diberikan kepada bagian tata usaha, oleh tata usaha data siswa tersebut diinput dan dari database data siswa dibuat untuk laporan data siswa untuk diserahkan kepada kepala sekolah.

2. Dari database data siswa dibuat data kelas, data kelas tersebut dicetak dan diberikan kepada siswa.

3. Database data kelas dibuat untuk pembuatan jadwal pelajaran.

4. Data guru diberikan kepada bagian Tata Usaha, oleh tata usaha data guru tersebut diinput dan dari database data guru tersebut dibuat untuk laporan kepala sekolah.

\section{Diagram Konteks}

Diagram konteks yang diusulkan dalam Sistem Informasi Akademik berbasis Dekstop pada Madrsah Aliyah Ar Rahmah Sungai Tabuk yaitu seperti gambar dibawah ini :

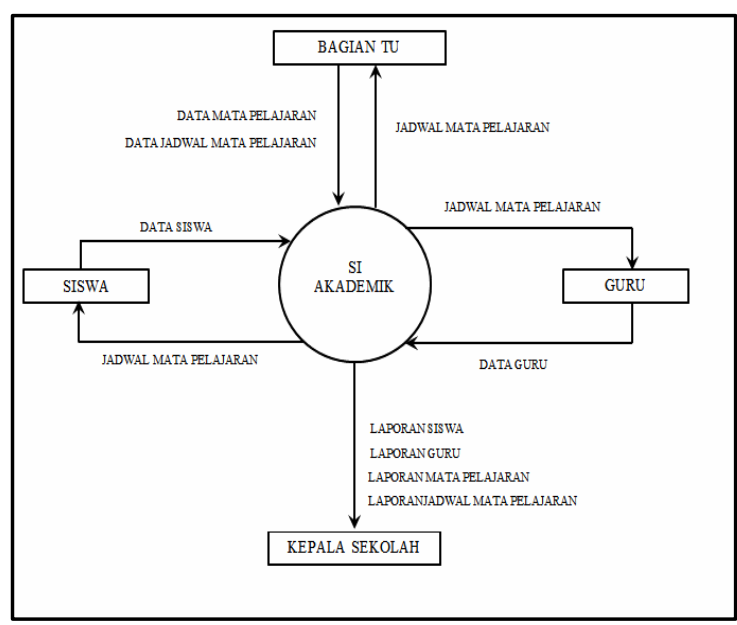

Gambar 1 Diagram Konteks

\section{Data Flow Diagram}

Berikut adalah tampilan gambar rancangan usulan DFD Level 0 :

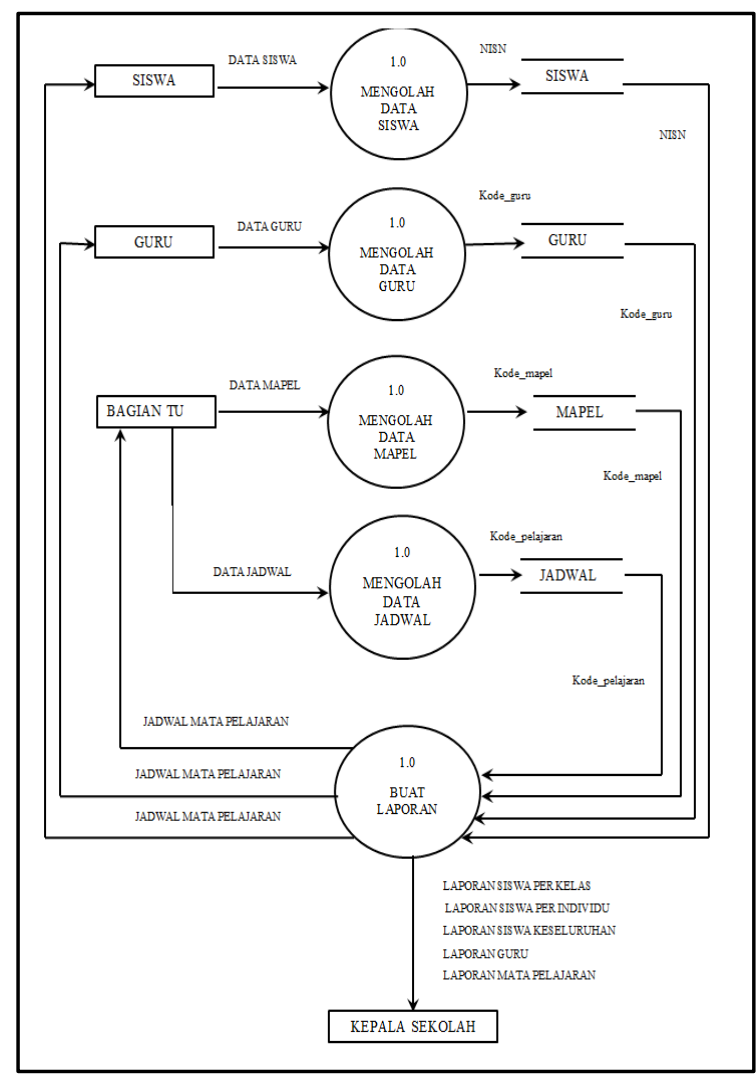

Gambar 2. Data Flow Diagram 


\section{Perancangan Antar Muka}

1) Struktur Menu

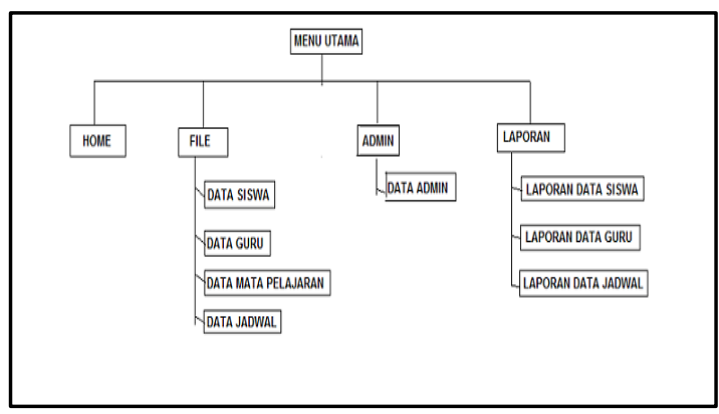

Gambar 3. Struktur Menu

\section{2) Tampilan}

Menu utama adalah form utama pada program. Form menu utama berguna untuk mengelola form lain. Pada Form menu utama digunakan untuk menampilkan submenusubmenu yang ada pada program yaitu menu file dan keluar dari program. Tampilan menu utama terlihat seperti gambar di bawah ini.

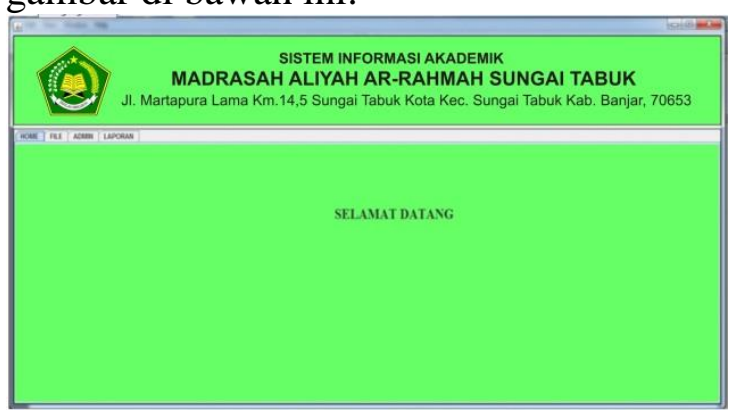

Gambar 4. Form Menu Utama

Form data siswa berguna untuk memasukan data siswa, mengedit, menghapus dan mencari Data Siswa. Untuk menjalankan sub menu ini adalah dengan memilih file siswa di menu utama, kemudian akan tampil form untuk mengisikan data-data siswa. Adapun tampilan input data siswa sebagai berikut :

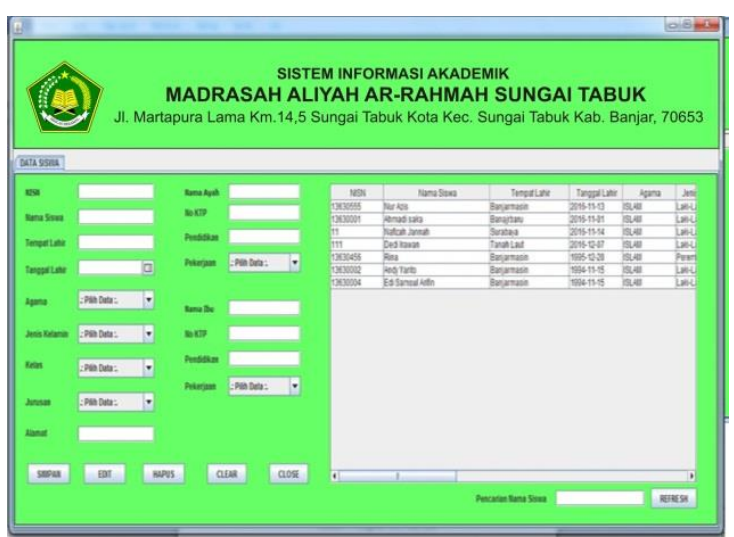

Gambar 5. Form Data Siswa

Form data guru berguna untuk memasukan data guru,mengedit, menghapus dan mencari data guru serta mencetak laporan data guru. Untuk menjalankan sub menu ini adalah dengan memilih file guru di menu utama, kemudian akan tampil form untuk mengisikan data-data guru. Adapun tampilan input data guru sebagai berikut :

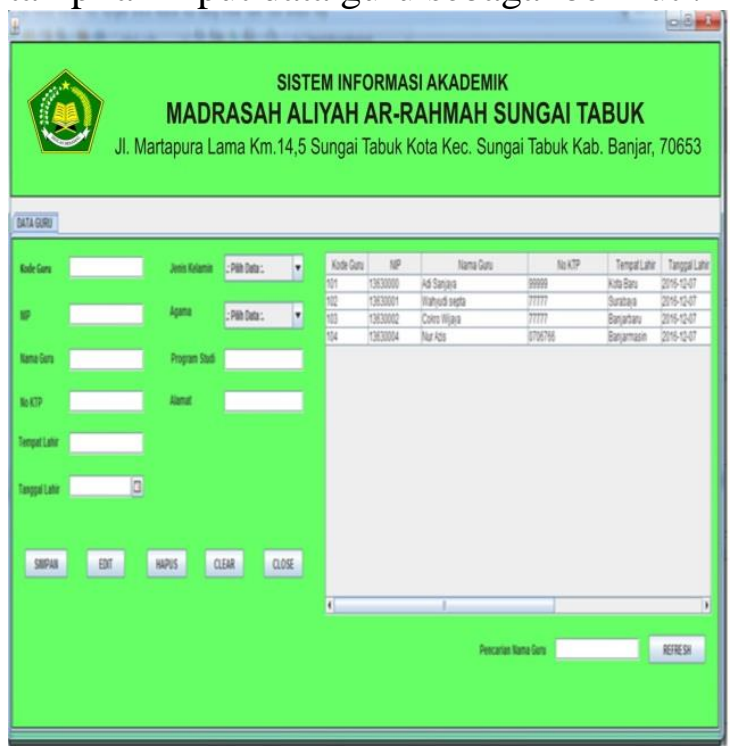

Gambar 6. Form Data Guru

\section{PENUTUP}

\section{Kesimpulan}

Dari hasil penelitian dapat dilihat bahwa pengolahan data menggunakan sistem konvensional kurang efektif dan kurang efisien untuk menghasilkan informasi yang dibutuhkan. Sedangkan penggunaan sistem yang baru dengan menggunakan sistem terkomputerisasi 
diharapkan informasi yang dihasilkan ini berkualitas dan dapat membantu proses kerja staff Tata Usaha.

Adapun beberapa kesimpulan yang dapat diambil dari sistem informasi yang dibuat adalah :

1. Staff Tata Usaha mengoptimalkan penggunaan komputer sebagai alat bantu dalam pengolahan data siswa untuk menyajikan informasi yang berkualitas.

2. Rancangan database yang dibuat dan berhubungan dengan sistem informasi akademik menggunakan MySQL sudah dapat disesuaikan dengan kebutuhan yang diperlukan oleh Madrasah Aliyah Ar Rahmah Sungai Tabuk.

3. Sistem Informasi Akademik Berbasis Desktop Pada Madrasah Aliyah Ar Rahmah Sungai Tabuk dapat menghasilkan informasi yang lebih akurat dalam hal pengolahan, pencarian dan pembuatan laporan data siswa, guru dan Jadwal.

\section{Saran}

Berdasarkan analisis dan kesimpulan diatas, juga sebagai pertimbangan bagi sekolah Madrasah Aliyah Ar Rahmah Sungai Tabuk dalam peningkatan pelayanan dan kinerja pegawai, saran yang ingin di sampaikan penulis adalah :

1. Sistem yang dibuat hanya sebatas pengolahan data siswa, guru, kelas siswa, dan jadwal. Sehingga masih banyak fitur yang perlu ditambahkan seperti pengolahan administrasi keuangan, dan laporan nilai siswa dan rapor.

2. Sesuai dengan kebutuhan pelayanan informasi sekarang dan untuk selanjutnya, di sarankan agar aplikasi ini nantinya dapat dikembangkan lagi menjadi aplikasi yang dapat digunakan untuk banyak pemakai (Multi User).

3. Untuk pemeliharaan aplikasi program ini perlu adanya evaluasi secara rutin sehingga dapat dilihat apakah perlu diadakan perbaikan atau penyempurnaan kembali.

4. Pengembangan sistem dapat lebih baik lagi bila dikembangkan menjadi berbasis website.

\section{DAFTAR PUSTAKA}

Budi Raharjo. (2011). Belajar Otodidak Membuat Database Menggunkan $S Q L$. Informatika Bandung.

Harnaningrum. (2009). Algoritma dan Pemrograman Menggunakan Java. Yogyakarta: Anda Offset.

Hasibuan, Z. A. (2007). Metodelogi Penelitian Pada Bidang Ilmu Komputer dan Teknologi Informasi. Jakarta.

Jogiyanto, \& Hartono. (2009). Analisis \& Desain Sistem Informasi. Yogyakarta. Andi Ofset.

Kadir, Abdul. (2008). Dasar Pemrograman Java 2. Andi. Yogyakarta.

Nugroho, Bunafit. (2006). Membuat Aplikasi Penjualan Dengan PHP dan MySQl. Yogyakarta: Ardana Media.

Simarmata, Janner 2006, Pengenalan Teknologi Komputer dan Informasi, Andi Offset, Yogyakarta 